\title{
College campus smoking policies and programs and students'
} smoking behaviors

\author{
Tyrone F Borders*1, K Tom Xu², Donna Bacchi ${ }^{3}$, Lee Cohen ${ }^{4}$ and \\ Danielle SoRelle-Miner ${ }^{5}$
}

\begin{abstract}
Address: ${ }^{1}$ Department of Health Policy and Management, University of Arkansas for Medical Sciences, Little Rock, Arkansas, USA, ${ }^{2}$ Division of Health Services Research, Texas Tech University Health Science CenterLubbock, Texas, USA, ${ }^{3}$ Department of Pediatrics and Center for Tobacco Control and Prevention, Texas Tech University Health Science Center, Lubbock, Texas, USA, ${ }^{4}$ Department of Psychology, Texas Tech University, Texas, USA and ${ }^{5}$ Center for Tobacco Control and Prevention, Texas Tech University Health Science Center, Lubbock, Texas, USA

Email: Tyrone F Borders* - ty.borders@gmail.com; KTom Xu - ke.xu@ttuhsc.edu; Donna Bacchi - donna.bacchi@ttuhsc.edu; Lee Cohen - lee.cohen@ttu.edu; Danielle SoRelle-Miner - danielle.sorelleminer@ttu.edu

* Corresponding author
\end{abstract}

Published: 07 July 2005

BMC Public Health 2005, 5:74 doi:10.1 I86/147I-2458-5-74
Received: 0I April 2005

Accepted: 07 July 2005

This article is available from: http://www.biomedcentral.com/I47/-2458/5/74

(c) 2005 Borders et al; licensee BioMed Central Ltd.

This is an Open Access article distributed under the terms of the Creative Commons Attribution License (http://creativecommons.org/licenses/by/2.0), which permits unrestricted use, distribution, and reproduction in any medium, provided the original work is properly cited.

\begin{abstract}
Background: Although tobacco use in the United States has declined over the past 20 years, cigarette use among college students remains high. Additional research is thus needed to determine how university tobacco control policies and preventive education programs affect college students' smoking behaviors.

Methods: Approximately 13,000 undergraduate students at 12 universities or colleges in the state of Texas completed a web-based survey. College smoking policies were obtained from a survey of college administrators and from college websites. Logistic regression analyses were conducted to estimate the effects of individual smoking policies and programs on the odds of cigarette smoking.

Results: Of the individual programs, only having a preventive education program on campus was associated with lower odds of smoking. The existence of smoking cessation programs and designated smoking areas were associated with higher odds of smoking. Policies governing the sale and distribution of cigarettes were insignificantly associated with smoking.
\end{abstract}

Conclusion: Rather than focusing on policies restricting cigarette sales and use, college administrators should consider implementing or expanding tobacco prevention and education programs to further reduce student smoking rates.

\section{Background}

Despite reductions in smoking rates over the past 20 years, tobacco use remains a key public health concern. According to recent estimates from the Centers for Disease Control, smoking is the leading cause of preventable death in the United States [1]. Cigarette use among college students is of particular concern as they have a substantially higher prevalence of smoking relative to the general adult population $[1,2]$.

To curb smoking rates on college campuses, several national organizations recommend that colleges and universities enact stricter tobacco control and prevention policies. The American College Health Association (ACHA) 
and American Cancer Society (ACS) advocate that colleges ban smoking in all campus buildings and residence halls; prohibit the sale, sampling, and advertising of tobacco products; restrict smoking to a minimum of 20 feet from building entrances and air intake units; limit or prohibit spit tobacco use on campus; and implement tobacco prevention/education and cessation programs on campus $[3,4]$.

Many institutions have responded to these recommendations. According to a survey of 50 colleges and universities across the United States, the number of campuses regulating cigarette use in student housing increased from $1 \%$ to 54\% between 1994-1995 and 2002-2003 [5]. A crosssectional survey of college students suggests that campus housing smoking bans are effective in decreasing smoking rates [6]. In addition to policies regulating where students can smoke, many universities have implemented public education campaigns aimed at non-smokers and smoking cessation programs targeting current smokers. According to a survey of health directors at 393 four-year universities across the U.S., $40 \%$ of schools offered some type of smoking cessation program [6]. Several studies have shown that anti-smoking messages can reduce smoking rates among younger adults [7-10], but little research has been conducted to assess their effectiveness among college students.

While there are some indications that more stringent tobacco policies and greater availability of promotion and prevention programs reduce smoking rates on college campuses, there is a lack of conclusive research in the area. More extensive regulatory policies could have a negative effect if they elicit a rebellious response from students. An additional question which remains insufficiently answered is the degree to which regulatory policies as compared to prevention or education are associated with smoking behaviors. An improved understanding of the relative effects of different types of policies and programs could assist college and university administrators as they consider how to invest resources to curb smoking.

\section{Methods \\ Survey sample}

A web-based survey, which was approved by Texas Tech University Health Sciences Center's institutional review board (IRB), was conducted among college students in Texas. The survey contained questions covering past and current cigarette, cigar, and smokeless tobacco use; knowledge of the risks associated with tobacco use; and responses to tobacco marketing campaigns. The sampling frame and methodology have been discussed elsewhere [11], but are briefly described here. All 72 colleges and universities within the state of Texas were invited to participate in a web-based survey of their undergraduate stu- dents' tobacco use. Of the 72 institutions, 27 did not elect to respond to requests to participate in the survey, 3 did not collect e-mail addresses from their students (which was necessary to recruit students), and 29 refused to release students' e-mail addresses. Thus, 13 college and universities agreed to participate in the study, representing 184,559 students.

Students from the participating schools were e-mailed and invited to participate in a web-based survey about tobacco use. To encourage participation, students were offered to enroll in a lottery to receive one of five $\$ 500$ airline gift certificates upon completion of the survey. They were then directed to a web site where they could complete the survey. Approximately $13 \%$ of students from the 13 participating schools completed the survey. For the analyses conducted here, one college was excluded because it had a particularly low response rate (approximately $2 \%$ ). Thus, the final sample represented 13,041 undergraduate students at 12 four-year colleges and universities in Texas.

\section{Variables}

Because we were concerned with the occurrence of smoking over a defined time period, as opposed to the quantity of cigarette consumption, we defined current smoking as having smoked at least one cigarette in the past 30 days. This is the standard method of categorizing persons as current vs. non-current smokers [6,12-14].

College-level campus smoking policies and regulations were obtained through mail surveys of college administrators. College administrators were asked whether their school had specific campus policies which restricted tobacco distribution, prohibited tobacco sales, restricted smoking to 20 feet from building entrances, prohibited smoking in student residence halls or dormitories, clearly identified non-smoking areas, prohibited tobacco ads in campus publications, prohibited events sponsored by tobacco companies, and prohibited smoking in all indoor public areas. They were also asked whether their school provided preventive education related to smoking and smoking cessation courses. Data collected from college administrators were supplemented by information obtained from each college's website.

Student-level control variables included the smoking status of a student's social circle (roommates and friends), academic information (college and academic classification), demographics (age, race/ethnicity, and gender), and memberships in certain groups (fraternity/sorority and intercollegiate sports team).

\section{Analyses}

To investigate whether universities' smoking policies and programs were significantly associated with the 
Table I: Descriptive Statistics of Sample

\begin{tabular}{|c|c|}
\hline College-level policies and programs & $\%(n=12)$ \\
\hline Restrict tobacco distribution & 58.3 \\
\hline Prohibit tobacco sales on campus & 16.7 \\
\hline Restrict smoking to $20 \mathrm{ft}$. from entrances & 16.7 \\
\hline Prohibit smoking in residence halls & 58.3 \\
\hline Clearly identify non-smoking areas & 41.7 \\
\hline Provide prevention and education & 41.7 \\
\hline Provide smoking cessation classes & 33.3 \\
\hline Student-level control variables & $\%(n=|3,04|)$ \\
\hline \multicolumn{2}{|l|}{ Age group (referent $=18-19$ ) } \\
\hline $20-21$ & 38.5 \\
\hline$\geq 22$ & 38.3 \\
\hline \multicolumn{2}{|l|}{ Race/Ethnicity (referent = white) } \\
\hline Hispanic & 11.7 \\
\hline Black & 2.6 \\
\hline Others & $1 \mathrm{I} .4$ \\
\hline \multicolumn{2}{|l|}{ Gender $($ referent $=$ male $)$} \\
\hline Female & 61.3 \\
\hline \multicolumn{2}{|l|}{ Roommate smokes (referent $=$ no roommate) } \\
\hline Yes & 27.8 \\
\hline No & 50.4 \\
\hline \multicolumn{2}{|l|}{$\%$ of friends who smoke (referent $=\leq 20 \%$ ) } \\
\hline $21-50 \%$ & 28.0 \\
\hline$\geq 50 \%$ & 15.5 \\
\hline \multicolumn{2}{|l|}{ College (referent $=$ applied science) } \\
\hline Arts & 15.7 \\
\hline Business & 18.2 \\
\hline Engineering & 8.6 \\
\hline Human Sciences & 11.8 \\
\hline Mass Communications & 11.7 \\
\hline Others & 21.7 \\
\hline \multicolumn{2}{|l|}{ Academic classification (referent $=$ freshman) } \\
\hline Sophomore & 14.7 \\
\hline Junior & 20.1 \\
\hline Senior & 28.1 \\
\hline Graduate & 22.2 \\
\hline \multicolumn{2}{|l|}{ Fraternity/sorority member $($ referent $=$ no) } \\
\hline Yes & 16.2 \\
\hline \multicolumn{2}{|l|}{ Intercollegiate athlete (referent $=$ no) } \\
\hline Yes & 4.6 \\
\hline
\end{tabular}

probability of smoking, multivariate logistic regressions were conducted. Among the ten policies, three (prohibition of tobacco advertisements in campus publications, events sponsored by tobacco companies, and smoking in indoor public areas) were present at all universities in the sample. Due to the lack of variation in these three policies, they were excluded from the analyses.

Univariate logistic regression analyses were first conducted to estimate unadjusted odds ratios for the university-level policies and programs. Student-level variables were included in the final multivariate model to control for their potential confounding effects. Because more than one student from each participating university was present in the sample, a traditional regression analysis was not used as it would provide larger standard errors of the estimated coefficients. To correct for the within-cluster dependence of the observations, a sandwich-like robust estimator of the variance-covariance matrix was used.

\section{Results}

The sample is described in Table 1 . Seven of the 12 schools $(58.3 \%)$ had a policy regarding tobacco distribution and prohibited smoking in residence halls. Only 2 $(16.7 \%)$ universities prohibited tobacco sales on campus and had restrictions on smoking to a minimum of 20 feet from entrances of buildings. Five schools $(41.7 \%)$ clearly identified non-smoking areas. Five schools $(41.7 \%)$ provided preventive education and four (33.3\%) delivered smoking cessation courses.

Approximately $37 \%$ of the students in the sample reported smoking in the past 30 days. The majority of the sample $(74 \%)$ was non-Hispanic white and about $61 \%$ was female. Although about half of the sample had roommates who smoked, only $16 \%$ reported that more than half of their friends were smokers. Approximately $16 \%$ of the students were members of fraternities or sororities. Fewer than 5\% were members of intercollegiate sports teams.

Table 2 shows the effects of universities' smoking policies and programs on the probability of smoking, controlling for students' characteristics. Only three of the seven policies or programs showed significant effects. Preventive education programs decreased the odds of smoking by about $23 \%$. In contrast, smoking cessation programs and the identification/designation of smoking areas significantly increased the odds of smoking by $30 \%$ and $45 \%$, respectively.

Estimation results indicated that student characteristics played a more important role in predicting smoking status. The smoking status of a students' social circle was significantly associated with smoking status. Also, maturity decreased the probability of being a smoker. As compared with freshmen, sophomores, juniors, seniors, and graduate students were significantly less likely to smoke. This pattern is mirrored in the age variable.

As compared with non-Hispanic white students, Hispanic and black students were less likely to smoke. Also, females were less likely to smoke, which is consistent with national level observations among adults [1]. Being a member of a fraternity/sorority or intercollegiate sports teams was not found to significantly contribute to the probability of smoking. 
Table 2: Unadjusted and Adjusted Odds Ratios (OR) for Current Smoking

\begin{tabular}{|c|c|c|c|c|}
\hline & Unadjusted OR (95\% Cl) & $p$ & Adjusted OR $(95 \% \mathrm{Cl})$ & $p$ \\
\hline \multicolumn{5}{|l|}{ College-level policies and programs } \\
\hline Restrict tobacco distribution & $1.12(0.82-1.52)$ & 0.48 & $1.00(0.90-1.11)$ & 0.97 \\
\hline Prohibit tobacco sales on campus & $0.82(0.67-1.02)$ & 0.07 & $0.95(0.83-1.08)$ & 0.43 \\
\hline Restrict smoking to $20 \mathrm{ft}$. from entrances & $0.83(0.67-1.03)$ & 0.09 & $0.91(0.79-1.04)$ & 0.15 \\
\hline Prohibit smoking in residence halls & $1.21(0.94-1.54)$ & 0.14 & $1.02(0.91-1.36)$ & 0.77 \\
\hline Clearly identify non-smoking areas & $1.48(|.2|-\mid .8 I)$ & $<0.01$ & $1.45(1.32-1.60)$ & $<0.01$ \\
\hline Provide prevention and education & $0.95(0.66-1.39)$ & 0.81 & $0.77(0.63-0.93)$ & $<0.01$ \\
\hline Provide smoking cessation classes & $0.95(0.66-1.37)$ & 0.80 & $1.30(1.17-1.45)$ & $<0.01$ \\
\hline \multicolumn{5}{|l|}{ Student-level control variables } \\
\hline \multicolumn{5}{|l|}{ Age group (referent $=18-19)$} \\
\hline $20-21$ & - & & $0.92(0.84-1.01)$ & 0.07 \\
\hline$\geq 22$ & - & & $0.85(0.74-0.98)$ & 0.02 \\
\hline \multicolumn{5}{|l|}{ Race/Ethnicity (referent $=$ white) } \\
\hline Hispanic & - & & $0.85(0.72-1.00)$ & 0.05 \\
\hline Black & - & & $0.51(0.37-0.69)$ & $<0.02$ \\
\hline Others & - & & $0.94(0.87-1.01)$ & 0.11 \\
\hline \multicolumn{5}{|l|}{ Gender $($ referent $=$ male $)$} \\
\hline Female & - & & $0.94(0.90-0.99)$ & 0.02 \\
\hline \multicolumn{5}{|l|}{ Roommate smokes (referent $=$ no roommate) } \\
\hline Yes & - & & $1.42(1.26-1.59)$ & $<0.01$ \\
\hline No & - & & $0.67(0.64-0.70)$ & $<0.01$ \\
\hline \multicolumn{5}{|l|}{$\%$ of friends who smoke (referent $=\leq 20 \%$ ) } \\
\hline $21-50 \%$ & - & & $2.62(2.46-2.79)$ & $<0.01$ \\
\hline$\geq 50 \%$ & - & & $6.44(5.45-7.60)$ & $<0.01$ \\
\hline \multicolumn{5}{|l|}{ College (referent $=$ applied science) } \\
\hline Arts & - & & $1.02(0.83-1.27)$ & 0.84 \\
\hline Business & - & & $0.91(0.79-1.03)$ & 0.14 \\
\hline Engineering & - & & $0.80(0.73-0.89)$ & $<0.01$ \\
\hline Human Sciences & - & & $0.96(0.82-1.12)$ & 0.62 \\
\hline Mass Communications & - & & $0.99(0.85-1.15)$ & 0.88 \\
\hline Others & - & & $1.18(1.02-1.37)$ & 0.03 \\
\hline \multicolumn{5}{|l|}{ Academic classification (referent $=$ freshman $)$} \\
\hline Sophomore & - & & $0.86(0.74-0.99)$ & 0.04 \\
\hline Junior & - & & $0.79(0.67-0.93)$ & 0.01 \\
\hline Senior & - & & $0.79(0.72-0.86)$ & $<0.01$ \\
\hline Graduate & - & & $0.59(0.50-0.69)$ & $<0.01$ \\
\hline \multicolumn{5}{|l|}{ Fraternity/sorority member $($ referent $=$ no $)$} \\
\hline Yes & - & & $1.09(0.98-1.22)$ & 0.12 \\
\hline \multicolumn{5}{|l|}{ Intercollegiate athlete (referent $=$ no $)$} \\
\hline Yes & - & & $0.93(0.80-1.07)$ & 0.30 \\
\hline
\end{tabular}

\section{Discussion}

Restriction of tobacco distribution, prohibition of tobacco sales, restriction of smoking within 20 feet from entrances, and prohibition of smoking in residence halls were not associated with the odds of smoking, suggesting that they are ineffective in influencing college students' smoking behaviors. Yet, other programs do appear to impact college students' smoking behaviors. We found that students enrolled at schools with smoking cessation programs had higher smoking rates, but this should not necessarily lead to the conclusion that smoking cessation classes contribute to smoking. It is reasonable to infer that administrators of colleges and universities that have higher smoking rates implement cessation programs in an attempt to reduce cigarette use. On the other hand, it has been shown that that college campus smoking cessation courses and programs are underutilized and that college students often want to quit on their own [15].

Prevention-oriented education was associated with lower odds of current cigarette use. Students who were exposed to education about smoking were 23 percent less likely to smoke compared their counterparts who were not exposed to campus education. There is little information 
about the efficacy of such campaigns on college campuses, but a number of studies have shown that anti-tobacco messages have a positive effect on tobacco use rates in other populations [7,9,10]. When Massachusetts evaluated the effects of its comprehensive state-wide tobacco control program on college students who were in high school when the program was initiated, results indicated that those students exposed to the tobacco prevention and education portions of the program had lower smoking rates than college students that were not exposed [14].

Although several of the policies and programs examined in this paper do not appear to affect current cigarette use, it is possible that others do affect college students' smoking status. Taking into consideration that all of the schools in the present sample prohibited tobacco advertisements in campus publications, events sponsored by tobacco companies, and smoking in indoor public areas, it was not possible to test for their effects on the odds of smoking. The latter three regulations may limit smoking to a point where the addition of other regulations has little impact. It should also be noted that the policies and programs discussed in the present paper could yield other, unmeasured benefits, such as reducing smoking rates among faculty and staff.

Despite the notable findings, the present study has a number of methodological limitations. Although the data set includes a large number of respondents, the participation rate could bias the results. The level of distribution and enforcement of policies was not measured, but could influence their effectiveness in controlling tobacco use [16]. Additional research is thus warranted to determine the degree to which college students are aware of published campus tobacco policies. Because we did not obtain detailed descriptions of the nature and content of preventive education and smoking cessation courses available on campus, we can not conclude whether particular programs are more effective than others.

\section{Conclusion}

In summary, results from the present study imply a need for additional evaluation of the effects of various approaches to tobacco control and prevention on student tobacco usage rates. Future studies should employ different methodologies whereby distinct conclusions about the effectiveness of specific policies or programs can be determined. In the interim, however, the present results suggest that prevention and education programs may have the strongest protective effect on college students' cigarette use.

\section{Competing interests}

The author(s) declare that they have no competing interests.

\section{Authors' contributions}

TFB conceived the study design, participated in data analysis, and led the writing of the manuscript. KTX assisted with data analysis and contributed to the writing of the manuscript. DB was responsible for conceiving the survey and overseeing data collection. LC assisted with the survey design and data collection. DSM assisted with data collection. All authors contributed to the writing of the manuscript.

\section{Acknowledgements}

This study was funded by the Texas Department of Public Health. The authors would like to thank Joel West and the Institute for Communications Research, Texas Tech University, for their assistance in conducting the survey.

\section{References}

I. Centers for Disease Control: Cigarette Smoking Among Adults-United States. MMWR 200I, 50:869-873.

2. Johnston LD, O'Malley PM, Bachman JG: Monitoring the Future National Survey Results on Drug Use, 1975-2002. Volume II: College students and adults ages 19-40. NIH Publication No 0353762003 [http://monitoringthefuture.org/pubs/monographs/ vol2 2002.pdf]. Accessed June 28, 2005

3. American College Health Association Subcommittee on Tobacco Intervention and Prevention: Position statement of tobacco on college and university campuses. [http://www.acha.org/ info resources/tobacco statement.pdf]. Accessed June 10, 2004

4. American Cancer Society's Smoke-Free New England Campus Initiative: Creating a Smoke-free Campus. [http://www.cancer.org/ docroot/COM/content/div NE/COM $42 \times$ Smoke-

Free New England.asp?sitearea=COM]. Accessed June 28, 2005

5. Halperin AC, Rigotti NA: US public universities' compliance with recommended tobacco-control policies. J Am Coll Health 2003, 5 I: $|8|-\mid 88$.

6. Wechsler H, Lee JE, Rigotti NA: Cigarette use by college students in smoke-free housing: results of a national study. Am J Prev Med 200I, 20:202-207.

7. Backinger CL, Fagan P, Matthews E, Grana R: Adolescent and young adult tobacco prevention and cessation: current status and future directions. Tob Control 2003, I 2(Suppl 4):IV46-53.

8. McVey D, Stapleton J: Can anti-smoking television advertising affect smoking behaviour? controlled trial of the Health Education Authority for England's anti-smoking TV campaign. Tob Control 2000, 9:273-282.

9. Borland R, Balmford J: Understanding how mass media campaigns impact on smokers. Tob Control 2003, I2(Suppl 2):ii45-52.

10. Goldman LK, Glantz SA: Evaluation of antismoking advertising campaigns. JAMA 1998, 279:772-777.

II. Morrell HER, Cohen LM, Bacchi D, West J: Predictors of smoking and smokeless tobacco use in college students: a preliminary study using web-based survey methodology. J Am College Health in press.

12. Rigotti NA, Lee JE, Wechsler H: US college students' use of tobacco products: results of a national survey. JAMA 2000, 284:699-705.

13. Emmons KM, Wechsler H, Dowdall G, Abraham M: Predictors of smoking among US college students. Am J Public Health 1998, 88:104-107.

14. Rigotti NA, Regan S, Majchrzak NE, Knight JR, Wechsler H: Tobacco use by Massachusetts public college students: long term effect of the Massachusetts Tobacco Control Program. Tob Control 2002, I I (Suppl 2):ii20-4.

15. Wechsler H, Kelley K, Seibring M, Kuo M, Rigotti NA: College smoking policies and smoking cessation programs: results of a survey of college health center directors. J Am Coll Health 200I, 49:205-2I2.

16. Pinilla J, Gonzalez B, Barber P, Santana Y: Smoking in young adolescents: an approach with multilevel discrete choice models. J Epidemiol Community Health 2002, 56:227-232. 


\section{Pre-publication history}

The pre-publication history for this paper can be accessed here:

http://www.biomedcentral.com/1471-2458/5/74/prepub

Publish with Bio Med Central and every scientist can read your work free of charge

"BioMed Central will be the most significant development for disseminating the results of biomedical research in our lifetime. " Sir Paul Nurse, Cancer Research UK

Your research papers will be:

- available free of charge to the entire biomedical community

- peer reviewed and published immediately upon acceptance

- cited in PubMed and archived on PubMed Central

- yours - you keep the copyright 